\title{
The Drosophila Couch potato protein is expressed in nuclei of peripheral neuronal precursors and shows homology to RNA-binding proteins
}

\author{
Hugo J. Bellen, ${ }^{1}$ Sandra Kooyer, Diana D'Evelyn, and Joel Pearlman \\ Howard Hughes Medical Institute, Institute for Molecular Genetics, Baylor College of Medicine, Houston, Texas 77030 USA
}

\begin{abstract}
Through enhancer detection screens we have isolated and cloned an essential gene that is expressed in the neuronal precursors and their daughter cells in the Drosophila embryonic peripheral nervous system (PNS). The gene is named couch potato (cpo), because several partial loss-of-function alleles cause hypoactive behavior in adults. Here, we present evidence that the structure of the cpo locus is unusually complex: It spans $>100 \mathrm{~kb}$, encodes three different messages, is differentially spliced, lacks an AUG initiation codon, and may encode three different proteins. Two putative Cpo proteins contain similar but nonidentical RNA-binding domains that are most homologous to the RNA-binding domains of the Drosophila embryonic lethal abnormal vision (elav) gene and a human brain protein that has been implicated in a paraneoplastic sensory neuropathy. Polyclonal antibodies raised against a fusion protein localize $\mathrm{Cpo}$ to the nucleus. Immunocytochemical studies demonstrate that the achaete-scute and daughterless genes are required for proper expression of cpo in the PNS but not in other cells that express cpo. On the basis of our observations, we present a model in which cpo is controlled by genes that determine cells to become PNS cells. Cpo, in turn, may control the processing of RNA molecules required for the proper functioning of the PNS.
\end{abstract}

[Key Words: couch potato; enhancer detection; peripheral nervous system; neural precurors; RNA-binding protein]

Received June 24, 1992; revised version accepted August 12, 1992.

To unravel the genetic and molecular pathway by which neurons differentiate, we have chosen to study the developing peripheral nervous system (PNS) of Drosophila. The cells of the embryonic PNS differentiate from neural precursor cells named sensory mother cells (SMCs). The SMCs are selected from small groups of lateral neuroectodermal cells, the proneural clusters. The SMCs delaminate from the proneural clusters into a subectodermal position and divide in a characteristic pattern to form sensory organs (Bodmer et al. 1989). The genes encoded by the Achaete-Scute Complex (AS-C) (Ghysen and Dambly-Chaudiere 1989a) and the daughterless (da) locus (Caudy et al. 1988a,b) are known to play key roles in determining which cells in the proneural clusters become competent to form SMCs. Embryos that lack AS-C or $d a$ genes lack many or all SMCs and PNS organs, and these genes have therefore been named proneural genes (Ghysen and Dambly-Chaudiere 1989a,b; Romani et al. 1989). The products encoded by the AS-C genes and the da gene are helix-loop-helix (HLH) proteins, which act as heterodimeric transcription factors (Murre et al.

${ }^{1}$ Corresponding author.
1989). It seems likely that these HLH proteins initiate the expression of a cascade of differentiation genes to form the sensory organs. Preliminary evidence indicates that similar mechanisms may also operate in the development of vertebrate PNS (Johnson et al. 1990; Lo et al. 1991; Johnson et al. 1992).

It is possible that the identity of a specific sensory organ is controlled by genes that act on subsets of SMCs. However, some genes may be required for all SMCs, controlling aspects of differentiation specific to the PNS. In an attempt to identify such PNS genes we have screened for genes that are expressed in most or all SMCs and their daughter cells using enhancer detector screens. This has permitted us to isolate an essential gene, couch potato (cpo), that is expressed in all SMCs (Bellen et al. 1992|. Behavioral and genetic studies have indicated that partial loss-of-function cpo alleles cause aberrant adult behavior because mutant cpo flies exhibit abnormal geotaxis, phototaxis, and flight behavior (Bellen et al. 1992). In this report we describe the structure of the cpo gene, the sequence of multiple cDNAs, the characteristics of the Cpo protein, and the distribution of the protein in different mutant backgrounds. Our observations suggest that $c p o$ may play a role as a PNS differentiation gene by 
regulating the processing of nervous system-specific transcripts.

\section{Results}

\section{Structure of cpo}

The cpo gene was identified through P-element-mediated enhancer detection. P-element insertion strains were selected that express $\beta$-galactosidase in the SMCs of the embryonic PNS and more differentiated cells of the PNS. Of 22 strains that express $\beta$-galactosidase in all SMCs (of 4500 lines screened), 15 were shown to contain an enhancer detector $P$ element at cytological subdivision 90D (Bellen et al. 1989, 1992; Bier et al. 1989; Wilson et al. 1989). Using plasmid rescue we isolated unique genomic fragments flanking the enhancer detectors and initiated the bidirectional walk shown in Figure 1. Approximately $110 \mathrm{~kb}$ of genomic DNA from cytological subdivisions $90 \mathrm{D}$ and $90 \mathrm{E}$ have been cloned.

We isolated 62 cDNAs by screening $\sim 10^{6}$ plaques (Zinn et al. 1988; Bellen et al. 1992). The three longest cDNAs, $61.1(3.4 \mathrm{~kb}), 17(3.0 \mathrm{~kb})$, and $61.2(2.5 \mathrm{~kb})$, were selected for further study. The cDNAs were hybridized to the genomic phages to construct a low resolution map. However, because the cDNAs as well as phages of the walk contain OPA repeats (Wharton et al. 1985), the high resolution map shown in Figure 1 was established by sequencing the three cDNAs (see Fig. 2) and the corresponding genomic fragments to which the cDNAs hybridized.

Sequence analysis of these cDNAs shows that they differ at both their $5^{\prime}$ and $3^{\prime}$ ends. The structure of the three cDNAs is shown in Figure 1 and described in the legend. The sequence of the three cDNAs is shown in Figure 2. We have also sequenced the exon-intron boundaries for the $61.1 \mathrm{cDNA}$. Most splice donor sequences are consistent with consenus sequences flanking Drosophila introns (Mount et al. 1992), with the possible exception of the splice donor at the boundary of exon 3 -intron 3 (see $3 \mathrm{~A}$ and $3 \mathrm{~B}$ at bottom of Fig. 2A sequence).

As shown in Figure 3, Northern analysis of 3- to 24hr-old embryos with unique probes derived from the $3^{\prime}$ end of 61.1 shows that the message from which the 61.1 cDNA is derived is $\sim 7.8 \mathrm{~kb}$ long. A probe derived from the 61.2 leader recognizes two messages of $\sim 4.5$ and 5.0 $\mathrm{kb}$, suggesting that another alternatively spliced product exists that does not correspond to an isolated cDNA. The Northern blot data show that the 61.1 and $61.2 \mathrm{cDNAs}$ are not full length. No typical polyadenylation signal is found upstream of the poly(A) tail, suggesting that they are the result of internal oligo(dT) priming. As shown below, preliminary evidence suggests that the sequences missing from 61.1 are confined to the $3^{\prime}$ end.

\section{Three different transcripts encode three different putative proteins}

Sequence analyses of three cpo cDNAs show that they contain three distinct, but overlapping, long open reading frames (ORFs). The $5^{\prime}$ ends of these ORFs are shared by the three cDNAs, but the ORFs differ at their 3 ' end owing to alternative splicing. Drosophila codon usage is respected throughout most of the common ORFs, but it

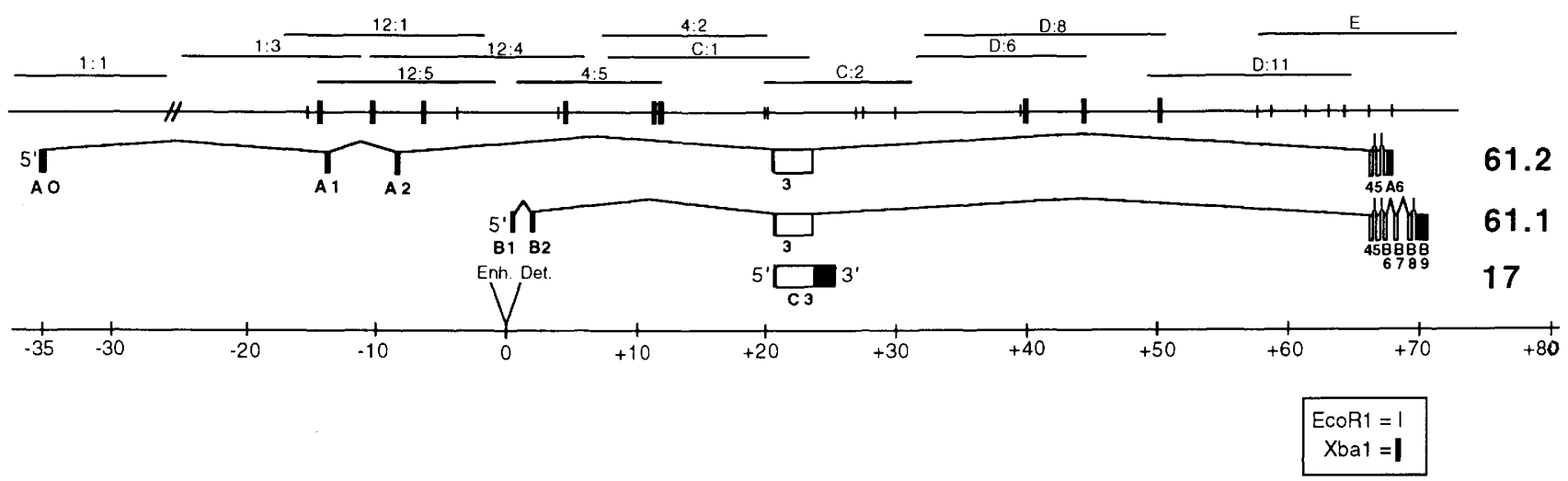

Figure 1. Structural map of the cpo locus. Map of genomic DNA and cpo transcription units. Genomic phage inserts spanning the region are shown above an $E c o \mathrm{RI}$ and $\mathrm{XbaI}$ restriction map. (As there are many EcoRI and HindIII sites in phages $1: 1$ and $1: 3$, not all sites have been mapped). The boxes below the map show the approximate size and location of the cpo exons of three different cDNAs (61.1, 61.2, and 17). Solid boxes represent leader and trailer sequences; open boxes represent ORFs. The leader of 61.2 (A) consists of three exons, $\mathrm{A} 0, \mathrm{~A} 1$, and $\mathrm{A} 2$; and the leader of 61.1 (B) contains two exons, $\mathrm{B} 1$ and $\mathrm{B} 2$. The $\mathrm{A} 2$ and $\mathrm{B} 2$ exons splice to a common third exon containing most of the ORF. The ORF initiates at the 5' end of exon 3 and extends into exons 4, 5, and A6 for $61.2 \mathrm{cDNA}$, and exons 4, 5, B6, B7, and B8 for 61.1 cDNA. Exon B6 is included in exon A6, but exon B6 splices to B7 in the middle of exon A6. The third exon is large for an internal exon $(1.5 \mathrm{~kb})$ and is followed by a $42-\mathrm{kb}$ intron. All of the remaining exons and many of the introns are small, except the last exons. The 17 cDNA contains only a single exon, C3, which is almost identical to the genomic DNA sequence. This cDNA is 15 nucleotides longer than A3 at the $5^{\prime}$ end and extends $\sim 1.7 \mathrm{~kb}, 3^{\prime}$ of exon 3 . The phage to which exon A0 maps has not been linked to the walk yet. All the enhancer detectors map at or close to position 0 . The sizes of introns and exons are shown in Fig. 2. 
C001 TAGITTTTGTAGGGICTCAGGACATTTCGCTTTCATGTTTGAAGTGGTCAOCCOCATTTCCACCACCGTT 0071 TTTGGACGGACACTCAACTGGCAGGCAGCTACCAGTACTTAAACAACCAAAAATAGAAACTAACTAAGTG 0141 CGI TTCTCTTAGCTAGATGGAGTCCACAGGCAOCGITCTCTTAGGATCCACTGTGGACCTACCICTTGCG 0211 CCCTCTTTTCGTTTTGGGGGGOCATTGGOGAACCGCAAAACCAAAACAAATGTGAGGAAAACACTCTCTC

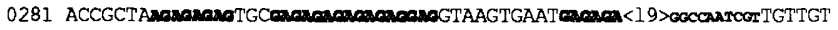

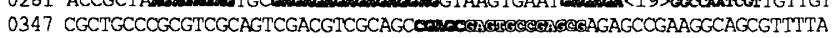

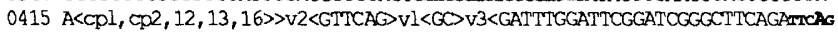
0455 TIITCA<11>GICTAATGTCAGGAACGCAGTTAGCTGCTCGICTCGTGCGGAACTCTCAAAACTGGOCGT 0521 TTAATATAACTAATAATCTAGCCGAATAATAAACAAACTGTAACTACAACOGGIAGCAGTAAGCAGTAAC 0591 TACACTACAGCAACTTAACAATCGGCCGTAACTCGAAATATT-GTAAATCAAAAAC..... int ron $1 .$. $06332.9 \mathrm{~kb}$. .CICATCCTCGGCAG-AACCATCAAAGTGAGGATATATCCCGAGAAAAAAAAAACOCAAACAAA 0681 GAAAAACAACCCAAAAAGAAAATTGGTGATACAAATTATTTGATTTGCGAAACCCAACTGAACACCOCAAAA 0751 AAADCCATAAATCCGTACATAAAACTACCAATATOGATATATACATATATAAATATATGTGAAAATCCCC 0821 AGAGTATATATATCAAACGCGAATAAAATAATTCAAAGTGGGCGGTGCAAAACAATTTGAAATCCTCTAC 0891 ACCAACGACGGCTACAAAAATTTCAATTACAGTGCAGCTGAAAAGTAAAACTTCACCAATCCAACAACCA 0961 ACACOCACACCAACGGAACGGCACAAAAACCAGTTAAAAGTGACTGGCAACACCAGCAGTAATAATAACT 1031 ACAAAAAG-GTAAAATATTTCA .... int ron $2 \ldots . .18 \mathrm{~kb} \ldots . .$. . TOCICTTTCGCAG-TTCAACTGA 1048 CTC GIC AAA ATA GOC AAC TAC CAG GAC CTG TTG GGC AGC CAT CAT CAA CTG CTC I leu val lys ile ala asn tyr gln asp leu leu gly ser his his gln leu leu
2 ATA GCC COC ACC GaCCOCC GCA GOC GCT GCA GCA GCC OCC GAA COG CAA CTG CAA 1102 ATA GCC COC ACC GaCCOCC GCA GOC GCT GCA GCA GCC GCC GAA CCG CAA CTG CAA
19 ile ala ala thr asp ala ala ala ala ala ala ala ala glu pro gln leu gln 19 ile ala ala thr asp ala ala ala ala ala ala ala ala glu pro gln leu gln
1156 CTG CAA CAC CTG TTG CCA GCA GOG CCG ACG ACA CCA GCA GTT ATT AOC AAT $C C T$ 37 leu gln his leu leu pro ala ala pro thr thr pro ala val ile ser asn pro 1210 ATC AAT TCG ATT GCC CCG ATC AAT CAG ATC ACC AGC AGC AGC CAT CCG AGC AAC 55 ile asn ser ile gly pro ile asn gln ile ser ser ser ser his pro ser asn 1264 AAC AAC CAG CAG GOG GTG TTC GAA AAA GCC ATC ACC ATT TOG TCG ATT GCG ATA 73 asn asn gln gln ala val phe glu lys ala ile thr ile ser ser ile ala ile 1318 AAA CGC AGG CCG ACG CTE COG CAG ACG CCA GCA AGT GCC CCA CAG GTG TTG TCC 91 lys arg arg pro thr leu pro gln thr pro ala ser ala pro gln val leu ser 1372 COG TCG COC AAG COC CAG TGT GOC GCCtGCC GIC TOC GIG CTG COG GIG ACC GT? 109 pro ser pro lys arg gln cys ala ala ala val ser val leu pro val thr val 1426 COC GIG COC GTT ऽOG GIG TOC GIA CCG CTG COC GTT TOC GTG COC GIG COC GTC 127 pro val pro val pro val ser val pro leu pro val ser val pro val pro val 1480 TOG GTC AAA GGT CAC COC ATC TOG CAC ACA CAC CAG ATC GOC CAC ACA CAC CAS 145 ser val lys gly his pro ile ser his thr his gln ile ala his thr his gln 1534 ATC TCG CAC TCG CAT $\propto$ CG ATC TCG CAT CCG CAC CAC CAC CAG CTG AOG TTC GCC 163 ile ser his ser his pro ile ser his pro his his his gln leu ser phe ala 181 his pro thr gln phe ala ala ala val ala ala his his gin gln gin gin gh 1842 CAC CAC COC CAG CAC CAG CA CAC GCC GT aCAA TAC CAA CAC CAC CAG GOC GT 199 gln gin ala gln gln gln gln gln ala val gln gln gln gln gln gln ala val 1696 CAG CAG CAA CAA GTT GCC TAC OCA GTT GCC QCC TCA CCA CAG TTG CAG CAA CAC $217 \mathrm{gln}$ gln gln gln val ala tyr ala val ala ala ser pro gln leu gln gln gln 1750 CAG CAG CAG CAG CAA CACgOGA CTG $\triangle C C$ CAG TIC AAC CAG GCG GCA GCA GCA GCI 235 gln gln gln gln gln his arg leu ala gln phe asn gln ala ala ala ala ala 1804 CTC CTG AAT CAG CAC TTG CAG CAG CAA CAC CAG GCG CAG CAG CAG CAA CAC CAA 253 leu leu asn gln his leu gln gln gln his gin ala gln gln gin gin his gln 1858 CCC CAG CAG CAA TCT CTG GCC CAC TAC GOC GSC TAT CAG CTG CAC AGA TAC GCA 271 ala gln gln gln ser leu ala his tyr gly gly tyr gln leu his arg tyr ala 1912 COG CAA CAG CAG CAG (CAG) CAG CAC ATC CTT CTG AGC AGC GSC AGC AGC ACC AGC 289 pro gln gin gln gln gln gln his ile leu leu ser ser gly ser ser ser ser 1963 AAG CAC AAC ACC AAC ACC AAC AGC AAC ACC AGT GCA GGA GGC GCA TCT GCG GCT 306 lys his asn ser asn asn asn ser asn thr ser ala gly ala ala ser ala ala 2017 GIG COC ATA OCA ACA TCC GIT OCT OCT GIC COG ACC ACC GOC GCC ACC TTG $\triangle C O$ 324 val pro ile ala thr ser val ala ala val pro thr thr gly gly ser leu pro 2071 GAC AGT COC QCC CAC GAA TOG CAC TCG CAC GAG TOC AAC TOC GOC ACC COC TOC 342 asp ser pro ala his glu ser his ser his glu ser asn ser ala thr ala ser 2125 OOG COG ACC ACG COC TOG $\bigcirc O G$ OCA GGC ACC GTC ACC ACC GOC GCC COC ACA OCA 360 ala pro thr thr pro ser pro ala gly ser val thr ser ala ala pro thr ala 2179 ACA GCA ACA CCC GCA GCA GCA GGA AGC GCgTGCA GCA ACA GCA GCA GCA 378 thr ala thr ala ala ala ala gly ser ala ala ala thr ala ala ala thr gly 2233 ACA CCA GCA ACA TCG OCC GIT ACC GAC ACC AAC AAC AAC CIC AAC ACC ACC AOC 396 thr pro ala thr ser ala val ser asp ser asn asn asn leu asn ser ser ser 2287 AOC AGC AAC AGC AAC ACC AAC GOC ATA ATG GAG AAT CAG AIG GCT CTG COC $O O C$ 414 ser ser asn ser asn ser asn ala ile met glu asn gln met ala leu ala pro 2341 TTG GGA CTT TCG CAG ACC ATG GAC TCC GIG AAT ACG GCC ACC AAT GAG GAA GAC 432 leu gly leu ser gln ser met asp ser val asn thr ala ser asn glu glu glu 2395 G-TGAGIGACAGCTT..... intron 3..42.7kb....GTCATCATTOCAG-TT CGC ACA CTT TTC

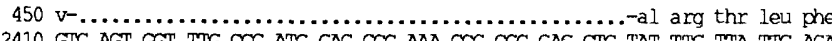
2410 GIC AGT GGT TTG COC ATG GAC GCC AAA OCG CGC GAG CTC TAT TTG TTA TTC AGA 455 val ser gly leu pro met asp ala lys pro arg glu leu tyr leu leu phe arg 2464 GCC TAT G-GTGAGITTTTCAT...... int ron 4..64bp......TACACAACAACAG-AG GCC TAT

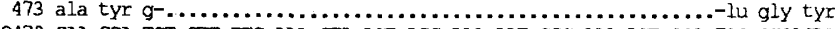
2479 GAA GGA TCT CTT TTG AAA GTA ACT AGC AAA AAT GCC AAA ACT GCA TCG-GICAGTA 478 glu gly ser leu leu lys val thr ser lys asn gly lys thr ala ser-...... 2527 AAGGTT.. intron 5..128bp....AAAATATTTACAG-COC GTT GCC TTT GTG ACA TTC CAT $494 \ldots \ldots \ldots \ldots \ldots \ldots \ldots \ldots \ldots \ldots \ldots \ldots \ldots$-pro val gly phe val thr phe his 2551 ACA AGA GCT GGA GCT GAG QCA QCT AAA CAG GAT CTG CAG-GTAAATATOCACA......

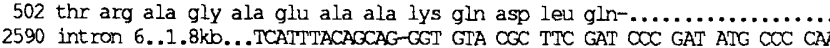
$515 \ldots \ldots \ldots \ldots \ldots \ldots \ldots \ldots \ldots \ldots$-gly val arg phe asp pro asp met pro gln 2620 ACA ATT COC TTG GAA TTC COC AAG AGT AAC AOG AAA GIG ACC AAA COC AAA CCA 525 ser asn thr lys val ser lys pro lys pro gln pro asn thr ala thr thr ala

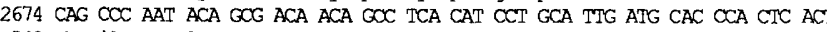
543 thr ile arg leu glu phe ala lys ser his pro ala leu met his pro leu thr 2728 GGA C-GTAAGTAAAAAAA.....intron $7 \ldots 2.4 \mathrm{~kb} \ldots .$. .TCTOGACTOGCAG-AT TTG GCC GGT $\begin{aligned} 561 & \text { gly } \mathrm{h}-\ldots \ldots \ldots \ldots \ldots \ldots \ldots \ldots \ldots \ldots \ldots \ldots \ldots \ldots \ldots \ldots \ldots \\ 2743 & \text { COC TTC TTT COG GOC GGA COS GAG TPA TGG CAT CAT COG CTA GCC TAT TOC GCA }\end{aligned}$ 566 pro phe phe pro gly gly pro glu leu trp his his pro leu ala tyr ser ala
2797 GCC GCC GCC ФCC GAA TTG $\triangle C A$ GGA ФCT GCT $C C A$ CTS CAT AGT GCA ACG CTA GTC 584 ala ala ala ala glu leu pro gly ala ala ala leu his ser ala thr leu val 2851 CAT COG GCC CTG CAT COG CAG GTG CCA GTG OGC TCC TAT CTC TGA CTAAATACAGA

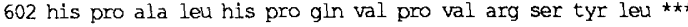

2907 CAAAGTAATGGAGCACCOCATGCATCAAACTCAA-GTAAGIGGAACSC............ int ron $8 .$.

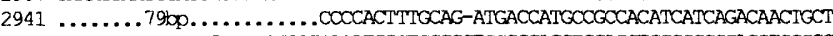
2974 ATTCATCCCGGACCTGCGATGGCTCACATGGCTGCGOCTGOCGCCAGCTGCAGCTGCOGGOGGAOGTGGGGC 3045 ACCGGCCACCCCTIGCTGCGGCACCGCAAAGT GCTOCTOCAACAGOOOCTGCAOCTGCTGCTGAATCACATC 3116 ACCACTATCTGTCGAGTOCGGCGITGGCCAGCCCOGCTGGATCTACGAACAACGCCAGTCATCOGGCCAAT 3187 CCACAGATCGCGOCCAATGCGCCCTGCTCCACGCTGTTTGTGGOCAATCTGGGGCAATTCGTTTCGGAGCA 3258 ○GAGCTGAAGGAGGIGITCTCTAGCAACAGCAGCAGCATCAACAGCAAGCAACAATCAACCAACAATCAGC 3329 AACAACAAAGGAGCGGGTATGGAATCACGSCATGATTTCCTCGCTAAAAAGCTAGAGCGOGAAATGCAGCA 3400 ACAGCAGACGCAAGTGCATCACCAGACGCAGCACCAACACCAGCAGCATCAOCACACAGCAGCGCAGCACT

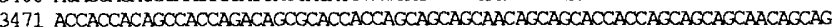

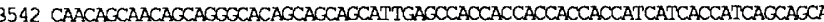
3613 GTTCTTGATGACOOCACOCT GACCTTATGOCACAAACGOOCAOCAOGACTAOGACGACGCCCCACCACGAC 3684 ОСАCATCAGCIOCACCAGOCGCAOCACCAACAGCAOCAOCAGCTCCAOCCGCACCACATCTACTCGTACGT 3755 GCIGCCGGCAGTCAGTCACATAGOGGCCTGAAGTGCCCACATTTGAGTTTGAGAAAATOGAGCCAAAGCTC 3826 OCCATCCAACGGATTCATGCGAGAAGTAAGAACCTTTAGTICTAGGCATACAAAAATAACAGAAAAAAAAA 3897 ATGTTGAAAAATCAAAAAAAAAAAAAAAA

\section{Comparison of Int ron-Exon Boundaries}

\section{\begin{tabular}{c} 
Int ron \\
\hline 1 \\
2 \\
$3 \mathrm{~A}$ \\
$3 \mathrm{~B}$ \\
4 \\
5 \\
6 \\
7 \\
8 \\
\end{tabular}}

TATT-GTAAATCAAAAAC

AAAG-GTAAAATATTTCA

GAGG-IGAGTGACACCTT

AGAG-GIGAGTGACACCI

TATG-GTGAGTTTTTCAI

ATOC-GIGAGTAAACGT'

GCAG-GTAAATATGCACA

GGAC-GTAAGTAAAAAAA

TCAA-GTAAGTGGAACOC

\begin{abstract}
Intron-Exon
TCAICCTCGGCAG-AAGC

GTCATCATTGCAG-TTCO

TGICATCATTGCA-GTTC

TACACAACAACAG-ACOO

AAAATATTTACAG-COOO

TCATTTACAGCAG-GGTC

TCTCGACTCGCAG-ATTT
\end{abstract}

0001 CAGGTTTGATACTCICGAACGCAAATGCTCGATCAAGACTGAAACATACGAGAAACATACAACTACAAAT 0071 GGTTCAACAAAGTATACGTAAAACTACCACAACCTAAACAAAATATAC-CAAAAAAAAATACACTG-... 0136 int ron $0 . . . .$. -AAATATCGATAATGAACIGAGAGACAGAGAGGCCGGAAAATACTCGAAAATGGIG 0191 ACATAAGATCGAG-GIAGAATAATGIC... intron $1 . .6 \mathrm{~kb} . .$. TCTCTGITITCAG-ACITTAATT 0213 GGCCTCCAATCGGAACCTCCGACCAATTTGTATACATTTTGITAACCAAG-...... int ron $2 \ldots$.

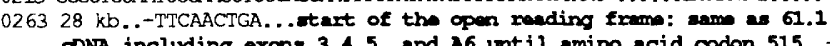
CONA including exons $3,4,5$, and $\lambda 6$ until amino acid codon 515 . 1826 GI'A AAT ATG CAC ATC ACA TAC ACA TAT ATC TCT GTA $O C T$ TTT ATA ATC GAA AGA 515 val asn met his ile thr tyr thr tyr ile ser val pro phe ile ile glu arg 1870 ACA CTA AAA TGA TTTAGCAAATTTGTATGAGCAATGCGACAAAAGAGAAAATGCCAGAAATATTTT

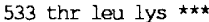

1936 CICAGCGACAAGAGIGTAGGTTACACACATAACATAAGAACTGTAAAGCACCCAATGAAAAAGTACTGAA 2006 ACTACGAAAATAACCAAAATACTTGIATACTCGTATTGCCTGGCITAAATACCTTTIAGGCCCCTGTTGCC 2076 GCTSCTCAAAAATCGACCITCGACCTCCTTTTGCATCACCCAAAAATCAAAAATCACCAAACAAAAAACA 2146 AATGATAGCAAAACAAAATACGAACAAGCAAACAAACAAACAACGATCCACACGAACACGIGCITGCAT 2216 TGAAAGAAAGAATCTTAAAATTCACCAAATCGCATTAAGIGTTTCCCTCTCTGTCTAGCCTTTGCTGTCC 2286 CQCTCTCTCTCTCICTCTATGTATCTCTATCTATCTCTCCATTTCIGTCGTTCTATATATCTCTCTCTAA 2356 CTTGCCATTEAGTTGTCTTATTGTTTTGGTATCTGCATCCCTCCTATTATTTGCTCATTCTACGAAAAC 2426 TCTTTGACADCCAGAAAACACAAATACACACGTAAACTGGTACACICATCACAACCACACACACACACAC 2496 ACCTACATCICTGGCAAAAAAAAAA

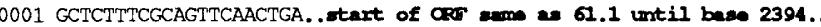
1369 GTG AGT CAC ACC TTC CAT TCC COC ATC CCA AAA GAT AAA CGA AAT AAA AAG CTG 450 val ser his ser phe his ser ala ile pro lys asp lys arg asn lys lys leu 1423 CAG ATA AAG ATA GCG TTG GGC GGG CAA AAA CGA AAA GGA TCT GGC CCC AGC AGC $468 \mathrm{gln}$ ile lys ile ala leu gly gly gln lys arg lys gly ser gly pro ser ser 1477 GAA ATG CGA CAA AAG TGA CAGCTTGGCGAATACAGAGTOCTGCATACTGAAATATIGCATAAAT 486 glu met arg gln lys $\star \star \star x$

1541 CGGIGGAAAGTCOCOCAAACTTCTCCTGGCACCTGAAAACTCTAAGIGGAGTAGTAGAATTTGGCCTAGA 1611 ATTTGCATTTKAGTACATAAGCAAGGTOCATGCAAATTGTTCTGGGGATTATCTTTTGGGGGGGGGGGG 1681 TGCTTGGATTICAAGAAATTCCTAGTACTAAAATTTGOCAGCTACCATCTTAAATTTAAAGCTTTTTGAA 1751 CAGTTIICATCTTGAAAATTTCCGGTAGCAACAATATTAAATTATTTCATTTCTTICATAGGGTATCCIT 1821 TOCTAAAAAAAATCACCCTTT'TCTCTCOCTTCACGACTTTGATTTATAGAGCTCAAATTAAAAGTTCATA 1891 AATTCAATCACATGIGTTGAAAGTATCCTTTTCAATCATTCGCTTTCGACTGAATCATTTAAACACTTTC 1961 GCACGATTTCCCCIOCAATAGAAAGTATGATOGATATGICGAGTGTTTCTGCCCCAATACAACCAACAOC 2031 CACTTGGAAAATCCOCTGAAATAATGGTGCGCTACATCAACTGGCACCTCGGCCGTAAGATTTTTGTGCO 2101 GCGCOCTITGITTTTGGOCAAAAAAAAGGGGGGACGACACCCTGCTGITITCTAAAACCCGGAAACGTGGC 2171 GGACGCAGGGAAGATGTGGGGOGATCCTTTGCACTTGIGTAAGTGSCATGTGCACCATTGGTGTTGCTAC 2241 TCCTGITGCAATGCGCTGITGITGCITACATTTTGATTATGCGCCTTGICTTATCCTACACATATTTCAC 2311 TTTCTICGCAGCAGCGIGOCACGCGTAATCCACGOGOCACGIGGCCCAGCGACCCAACCCATCAAGCCAA 2381 GCTOCITCCCITTCATACCACTGIACCACCCCACOCACCAAACCACOGACCACCCATOGITTGOCTCGCI 2451 GCACTGCCTTCATGICAAGTGGGTACGIGGCCITACACGCACACAAAGGCCGTCGITTGTGAGGGGGGGT 2521 TGGITTAAAAAAAAGGGGGGGGGGGICIACCACTACTACOGAAGCGATGCGITAAATTTGATTTTATCCIT 2591 GATAAATAAATOCICITACTITTGITTTACTCTACCCATICCAACTACGCTIATGGATTTTTATGCGCGC 2661 GIGATTTTGGGAAAITTATTGAAGICCTATCGCACAGGITTGCTGAATAGITGGCAAGAGCTTAATGCCA 2731 TGGGAAAAGITGGACTGAAGATTTAGITTAAAGCGGCCAGAATAGIGCAGCAGATATATTTTAAGATTTT 2801 TAAATCTTAGCCTAATCCAACTGGGATGIGITTGCAAAGCACAGATGCACAGAAAACCTTTTGCCGCCIT 2871 GCICCIGGAITTAGICCACGGAAATTCGCATTAAAAATGCATCAATCACTTGGTTCCCACTTGCTCCACT 2941 TCACTCTCCGCAACCCTCTGCAGTTTCTCGCCAAAATGAAAGGCAAGGAAAATCCAGGTOGGTGGAAGAT 3011 AAAGTTCCACATGAAAAAACGAATT

Figure 2. (See following page for legend.) 
is respected poorly at the $5^{\prime}$ and $3^{\prime}$ ends of the ORFs. A number of much shorter ORFs can be identified in the three cDNAs, but these have generally poor Drosophila codon usage. Although the first methionine codon within the ORFs occurs at codon 423 , several lines of evidence suggest that translation is initiated upstream of this site in embryos. First, the context of codon 423 does not conform well to the Drosophila consensus for translation initiation (Cavener 1987). Second, Drosophila codon usage is maintained upstream of codon 423 and drops abruptly between codons 30 and 40 of the ORFs, suggesting that most of the ORF is translated. Third, the products of translation initiating at codon 423 have predicted molecular masses of $22 \mathrm{kD}$ or less, far smaller than the $50-\mathrm{kD}$ products detected on immunoblots. Fourth, in vitro translation shows that the three cDNAs can be translated, albeit at low efficiency, into several proteins, including a $50-\mathrm{kD}$ protein (data not shown). Fifth, extensive sequencing of genomic fragments encoding the sequences for the cDNA did not reveal sequencing mistakes. These observations suggest that translation is initiated upstream of codon 423 , possibly between codons 30 and 40 .

The putative proteins encoded by the three ORFs can be subdivided into four domains on the basis of amino acid composition (Fig. 2). These domains are a polyalanine-rich stretch, followed by a proline- and histidinerich domain containing a putative bipartite nuclear translocation signal (Robbins et al. 1991) and seven P-V/ I/A-S-V/A/H-P repeats of unknown significance (1193); an OPA repeat (194-296) (Wharton et al. 1985); a serine-rich region with two homopolymeric stretches and serine-alanine repeats (297-426); and a domain that is different in each clone. This domain contains an 80 - amino-acid core sequence in 61.1 and 61.2 cDNAs: the ribonucleoprotein consensus-type domain (RNP-CStype) found in many RNA-binding proteins. The Cpo RNP-CS-type domains are most homologous to a human brain protein (HuD) (Szabo et al. 1991) and its Drosophila homolog embryonic lethal abnormal vision (elav) (Robinow and White 1988). Both ELAV and HuD are expressed in the nervous system and contain three RNP-CS-type domains, whereas cpo cDNAs only contain one RNP-CS-type domain. The two Cpo RNP-CStype domains differ in 15 amino acids at their carboxyl terminus owing to differential splicing (italicized in Fig. $4 \mathrm{~B})$.

\section{P-element enhancer detectors are inserted in key regulatory sequences}

Genetic evidence indicated that key regulatory sequences of $c p o$ are present in the vicinity of the enhancer detectors. Southern blot analysis showed that all of the $\mathrm{P}$ elements are clustered in a 200-bp genomic fragment just upstream of the $5^{\prime}$ end of the $61.1 \mathrm{cDNA}$. To show that the sequences surrounding the enhancer detectors contain $c p o$ regulatory sequences, a $10-\mathrm{kb} X b a \mathrm{I}$ genomic fragment (derived from wild-type DNA present in phage 12:4; see Fig. 1) carrying these putative regulatory sequences, as well as the B1 and B2 exons and the first intron, was fused to a heterologous promoter driving expression of the lacZ gene (Hiromi and Gehring 1987). Embryos of two independently transformed strains were stained with an anti- $\beta$-galactosidase antibody. As shown in Figure 5, the expression pattern of lacZ essentially corresponds to the expression pattern observed in the enhancer detector strains. However, staining in many

Figure 2. (A) Nucleotide sequence of the cpo $61.1 \mathrm{cDNA}$, its $5^{\prime}$-flanking genomic DNA, the insertion sites of the enhancer detectors, and the predicted amino acid sequence of the cpo ORFs. Putative binding sites for transcription factors in genomic flanking sequences are shadowed or shown in small, bold uppercase letters. They correspond to three GAGA protein-binding sites, a C/EBP-binding site, and three Zeste-binding sites. The single bold underlined uppercase letter corresponds to the first nucleotide of the longest of three independently isolated cDNAs of the 61.1 type. The bold A in TTCAGTTT corresponds to the putative transcription start site. The insertional location of 10 enhancer detectors is shown. Enhancer detectors that are in the same orientation $\left(5^{\prime} \rightarrow 3^{\prime}\right)$ as cpo transcription are shown between angle brackets $\langle\langle\rangle|$, those inserted in the opposite orientation $\left\langle 3^{\prime} \rightarrow 5^{\prime}\right\rangle$ are shown between inverted angle brackets ( $(X)$. (1) Lethal; (cp) Couch potato phenotype; (v) viable [see Bellen et al. (1992)]. The insertional consensus for the 8 nucleotides next to the 10 P elements shown here is GXTCAGGC. O'Hare and Rubin (1983) found GGCCAGAC. Exon-intron and intron-exon boundaries are hyphenated and followed or preceded by 13 genomic nucleotides. The sizes of the introns are indicated. The longest ORF is translated. In the absence of an AUG initiation codon, the first codon was numbered 1 . The splice donor and splice acceptor sites are tabulated below the sequence. The boundaries of the third intron cannot be determined and the two alternative possibilities are shown as $3 \mathrm{~A}$ and $3 \mathrm{~B}$ (Fig. 2). In either case, the splice donor or the splice acceptor site does not conform to the consensus. Two and possibly three splice acceptor sites do not conform to the consensus (Mount et al. 1992). Those of introns 4 and 5 contain few pyrimidines when compared with most splice acceptor sites. The estimated molecular mass of the protein if the entire ORF is translated is $64 \mathrm{kD}$. Differences were observed between the cDNA sequence and the genomic cDNA: at 1115, the genomic sequence is $C_{\text {; }}$ at 1398, the genomic sequence is $\mathrm{T}_{\text {; }}$ at 1578-1582, the genomic sequence is TGAC; at 1671, the genomic sequence is $\mathrm{A}$; at 1767 , the genomic sequence is G. Between 1926 and 1927, the 61.2 CDNA has an additional CAG repeat, which is not present in the genomic DNA and the 61.1 cDNA. At 2208, the genomic sequence is T. $(B)$ Nucleotide sequence of the 61.2 cDNA. Only the sequences that are not shared between the 61.2 and 61.1 cDNAs are shown. The leader consists of at least three exons (A0, A1, and A2), but the boundary between exon $\mathrm{A} 0$ and intron 0 has not been determined precisely. This cDNA shares exons 3,4 , and 5 with 61.1 . Exon A6 is only partly shared by the two cDNAs. A6 remains contiguous with the genomic DNA, whereas the $61.1 \mathrm{cDNA}$ splices to exon B7 at 2588. The estimated molecular mass of the protein if the entire ORF is translated is $56 \mathrm{kD}$. (C) Nucleotide sequence of the $17 \mathrm{cDNA}$. The 17 cDNA consists of a single exon, C3. It contains $15 \mathrm{bp}$ upstream of exon 3 of the $61.1 \mathrm{cDNA}$ and $1.7 \mathrm{~kb}$ downstream of the site where 61.1 and 61.2 are spliced off. It shares only exon 3 with 61.1 and 61.2. The estimated molecular mass of the protein if the entire ORF is translated is $51 \mathrm{kD}$. 


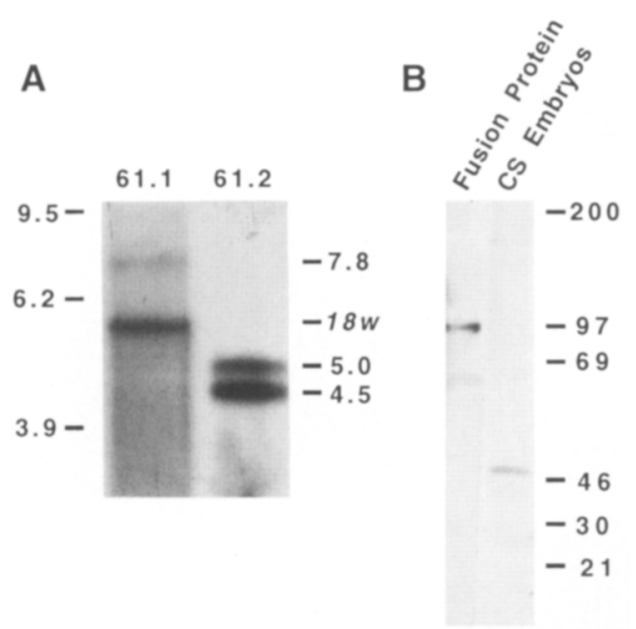

Figure 3. cpo Northern analysis and Cpo immunoblot. $(A)$ Northern blots. Ten micrograms of poly $(\mathrm{A})^{+}$RNA isolated from 3- to 24 -hr-old embryos was run on an $0.8 \%$ agarose gel, transferred to a membrane, and hybridized with different probes. Northern analyses with a probe derived from 61.2 , which contains sequences shared by the three cDNAs $\mid \mathrm{A} 0, \mathrm{Al}, \mathrm{A} 2$, and 500 nucleotides of $A 3$ ), detects three transcripts of $4.5,5.0$, and 7.8 $\mathrm{kb}$ in 6- to 22-hr-old embryos (data not shown). This indicates that cpo encodes at least three embryonic transcripts. We detect faint or no hybridization signals with this probe at later developmental stages, except in pupae. The Northern blots shown here were hybridized with a 400-bp BgII fragment of 61.1 and with a 150-bp ClaI fragment for 61.2. Both probes are unique. No signal has been observed on the same Northern blots with probes derived from the 3' trailer of the $17 \mathrm{cDNA}$. However, this 17 cDNA fragment identifies a transcript in situ that is expressed faintly in many PNS cells early in development. At later stages of development, this transcript is expressed only in the neurons of the chordotonal neurons (see Fig. 7B). $18 \mathrm{~W}$ is a Drosophila gene that encodes a 5.8 -kb transcript (B. Eldon, pers. comm.). It is shown as a molecular mass marker. (B) Immunoblots of bacteria that express the Cpo fusion protein and 3- to 24-hr-old Canton-S embryos. The anti-Cpo antibody recognizes a single band in embryonic extracts that corresponds to a protein of $\sim 50 \mathrm{kD}$.

cells of the external sensory organs is much fainter than in other cells that express the $\beta$-galactosidase. Hence, $<10 \%$ of $c p o$ contains most regulatory sequences used in embryogenesis.

To further characterize putative regulatory sequences the genomic region immediately upstream of the $5^{\prime}$ end of the 61.1 cDNA was sequenced. As shown in Figure 2, this sequence contains many putative binding sites for known Drosophila transcription factors: three GAGAGA-binding sites (Biggin and Tjian 1988); three partially overlapping CGAGC/TG sites or Zeste-binding sites (Benson and Pirrotta 1988; Biggin et al. 1988); and a CCAAT box or C/EBP-binding site (Johnson et al. 1987; Friedman et al. 1989). There is also a Drosophila consensus sequence for a trancription initiation site (TCAGTT) 22 nucleotides upstream of the first nucleotide of the longest cDNA (Hultmark et al. 1986; Pirrotta et al. 1987; Burtis et al. 1990). The positions of 10 different enhancer detectors were determined by sequencing the P-element boundaries. Insertions that cause homozygous lethality are indicated with 1 , those that cause a cpo phenotype and fail to complement 1 insertions are abbreviated $c p$, whereas others are abbreviated $v$ (Fig. 2; Bellen et al. 1992). As shown in Figure $2 \mathrm{~A}$, eight enhancer detector insertions $(c p 1, c p 2,12,13$, $16, v 2, v 1, v 3)$ are located between the putative zestebinding sites and the putative transcription start site. Six P elements $(c p 1, c p 2,12,13,16, v 2)$ have inserted at exactly the same position ( 0 in walk shown in Fig. 1) but cause very different defects: The $c p 1$ and $c p 2$ insertions are 17-kb P[1ArB] insertions (Wilson et al. 1989) and cause behavioral defects in adults; 12,13 , and 16 insertions are $10-\mathrm{kb} P\left[\mathrm{lacZ}, \mathrm{w}^{+}\right]$insertions, which cause homozygous lethality; $\mathrm{v} 2$ is a $\mathrm{P}\left[\mathrm{lacZ}, \mathrm{w}^{+}\right]$insertions, inserted in the opposite orientation relative to the other five, and no obvious phenotype has been associated with this insertion. Previous studies have shown that the $c p 1$ and $l 2 \mathrm{P}$ elements can be excised leading to a concomitant reversion of the phenotypes (Bellen et al. 1992). Hence, the phenotype associated with enhancer detectors that are inserted at exactly the same position is dependent on size, type, or orientation of the P element.

\section{Cpo is a nuclear protein}

To characterize the Cpo protein, an antibody was generated against a TrpE-Cpo fusion protein. As shown in Figure 6, this antibody recognizes an antigen that is most abundant in the neurons and support cells of the PNS, less abundant in a number of glial cells of the PNS and central nervous system (CNS), and barely detectable in cells of the gut of some embryos. Some faint and diffuse staining is also observed in the CNS.

The $\beta$-galactosidase expression pattern in the enhancer detector strains and the anti-Cpo staining pattern in double-labeled embryos are very similar. In addition, some $c p o$ mutant embryos lack the protein recognized by the anti-Cpo serum in most cells in which it is normally found. Hence, the histochemically detected protein most likely corresponds to the Cpo protein. As shown in Figure 3B, the anti-Cpo serum detects a single band of $\sim 50 \mathrm{kD}$ on an immunoblot of embryonic extracts.

Double-labeling experiments with the anti-Cpo antibody and the anti- $\beta$-galactosidase antibodies (Fig. $5 \mathrm{~B}$; data not shown) show that Cpo is localized to the nucleus. Little or no label is observed in the cytoplasm. This indicates that the protein is actively transported into the nucleus and/or that its presumed affinity for pre-mRNA sequences leads to nuclear retention (Swanson et al. 1987). Nuclear localization is observed in the cells of the PNS, some glial cells of the CNS, and the cells of the gut (see Fig. $6 \mathrm{C}$ ). We have been unable to exclude the possibility that cpo may be present at low levels in the cytoplasm and nuclei of CNS neurons.

Cpo expression in wild-type and mutant embryos

The developmental expression pattern of cpo mRNA has 
A

\begin{tabular}{cccccc} 
Amino Acid \# & \multicolumn{3}{c}{ Amino Acid sequence } \\
\hline 100 & P & A & S & A & P \\
118 & A & V & S & V & L \\
123 & P & V & T & V & P \\
131 & P & V & S & V & P \\
137 & P & V & S & V & P \\
143 & P & V & S & V & K \\
168 & P & I & S & H & P \\
\hline Consensus & P & V & S & V & P
\end{tabular}

\section{B}

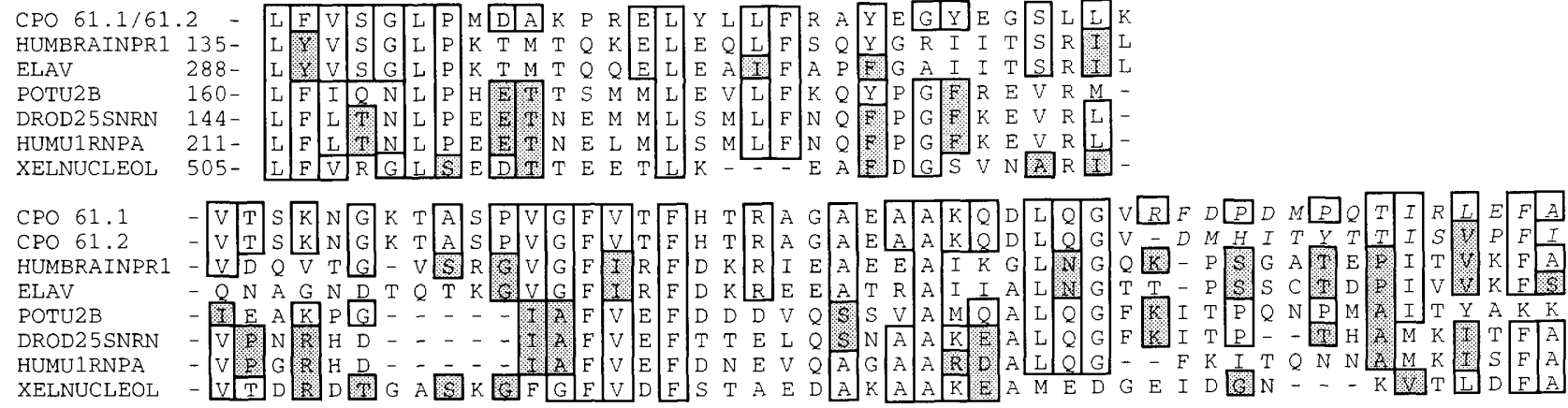

Figure 4. (A) A novel type of repeat sequence in Cpo: PVSVP. A consensus repeat sequence, PVSVP, can be derived by comparing the amino acid sequence in the carboxyl terminus portion of domain $1 .(B)$ Comparison of the putative RNA-binding domains of the Cpo protein with other known RNA or single-stranded DNA-binding proteins. Identical and conserved amino acids are boxed. The italicized stretch of carboxy-terminal amino acids are different between 61.1 and 61.2. The two most conserved domains correspond to the ribonucleoprotein consensus 1, or RNP1 (LFVSGLP), and RNP2 (PVGFVXF) found in many RNA-binding proteins. The RNPCS-type domains of Cpo is more homologous to two proteins that contain three RNP-CS-type domains and are expressed in the nervous system: ELAV and HuD (Monte Carlo score, Cpo 61.1-ELAV = 6.87; Cpo 61.1-HuD = 12.26; Cpo 61.2-HuD = 13.92; Cpo 61.2-ELAV $=7.42$; a score $>6$ means probable homology). Other RNA-binding proteins (with GenBank accession number) shown are Potato spliceosomal U2B protein (M72892), Drosophila D25 small nuclear ribonucleoprotein (M89775), human U1 small nuclear RNA-binding protein (X06347), and Xenopus nucleolin RNA-binding protein (X63091).

been described previously (Bellen et al. 1992). The expression pattern of the Cpo protein in wild-type embryos is shown in Figure 6. Briefly, Cpo expression is initiated in the SMCs at maximal germ-band extension after the first signs of segmentation appear (Fig. 6A). During germband retraction, the pattern becomes complex: Many precursor cells as well as more differentiated cells of the PNS express Cpo. Later, during embryogenesis, most cells of the PNS express Cpo (Fig. 6B,E). Some support cells of the extra sensory organs express Cpo very weakly or not at all. Other cells that express Cpo are located on the dorsal and ventral sides of the CNS (Fig. 6D). The positions and shapes of these cells suggests that they are glial cells. The expression pattern in the nervous system corresponds to the expression of cpo messages (Bellen et al. 1992).

Cpo protein expression is also seen in the developing gut. Staining in these cells is faint and easily overlooked. As shown in Figure 6C, most of the expression in late embryos is confined to the more posterior parts of the midgut. Contrary to the expression in the PNS and the CNS, cpo expression in the gut was not observed in whole-mount in situ hybridizations (Bellen et al. 1992).

The Cpo protein distribution was analyzed in several mutant strains that carry different $c p o$ alleles. As shown in Figure 7A, embryos homozygous for the most severe cpo alleles [the 11 enhancer detector insertion or a small deficiency that removes some of the regulatory sequences (Bellen et al. 1992)] lack the protein in all cells that normally express Cpo except the chordotonal neurons. These neurons only express Cpo late during embryonic development, whereas wild-type embryos express Cpo earlier in the SMCs and their progeny. The protein expression pattern in these two mutants corresponds to the RNA in situ expression pattern seen in these mutants (Bellen et al. 1992). It also corresponds to the pattern observed when a probe specific for the 17 cDNA is used (Fig. 7B). The Cpo protein was also immunocytochemically localized in many other cpo mutants described previously (Bellen et al. 1992). Embryos homozygous for all other lethal alleles tested, with the exception of 19 , show reduced levels of Cpo expression, consistent with the decreased mRNA levels observed in these mutants (data not shown). However, no visible changes in levels or pattern of expression were observed in homozygous viable cpo mutants or homozygous 19 embryos. The 19 insertion is $\sim 120$ nucleotides upstream of the transcription start site, and on the basis of genetic criteria this allele was classified as a weak hypomorphic homozygous lethal allele (Bellen et al. 1992). 

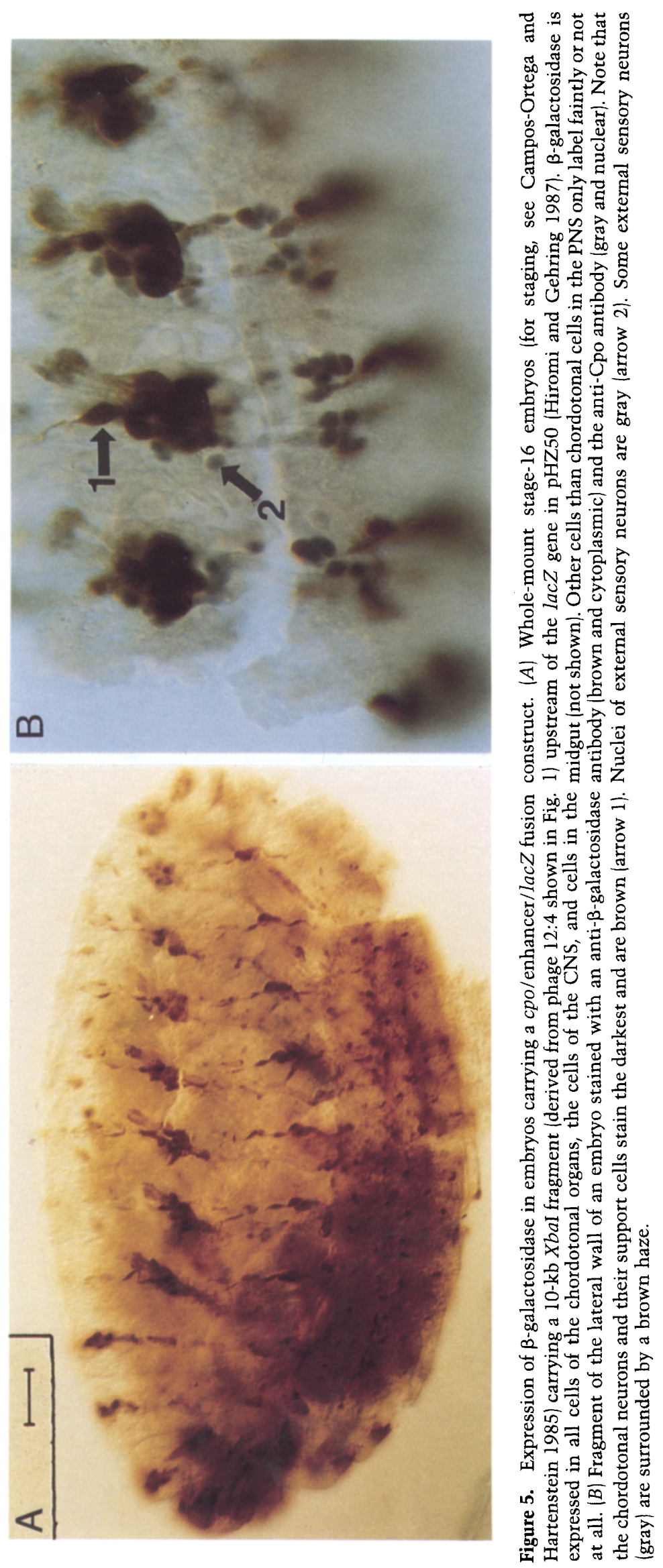

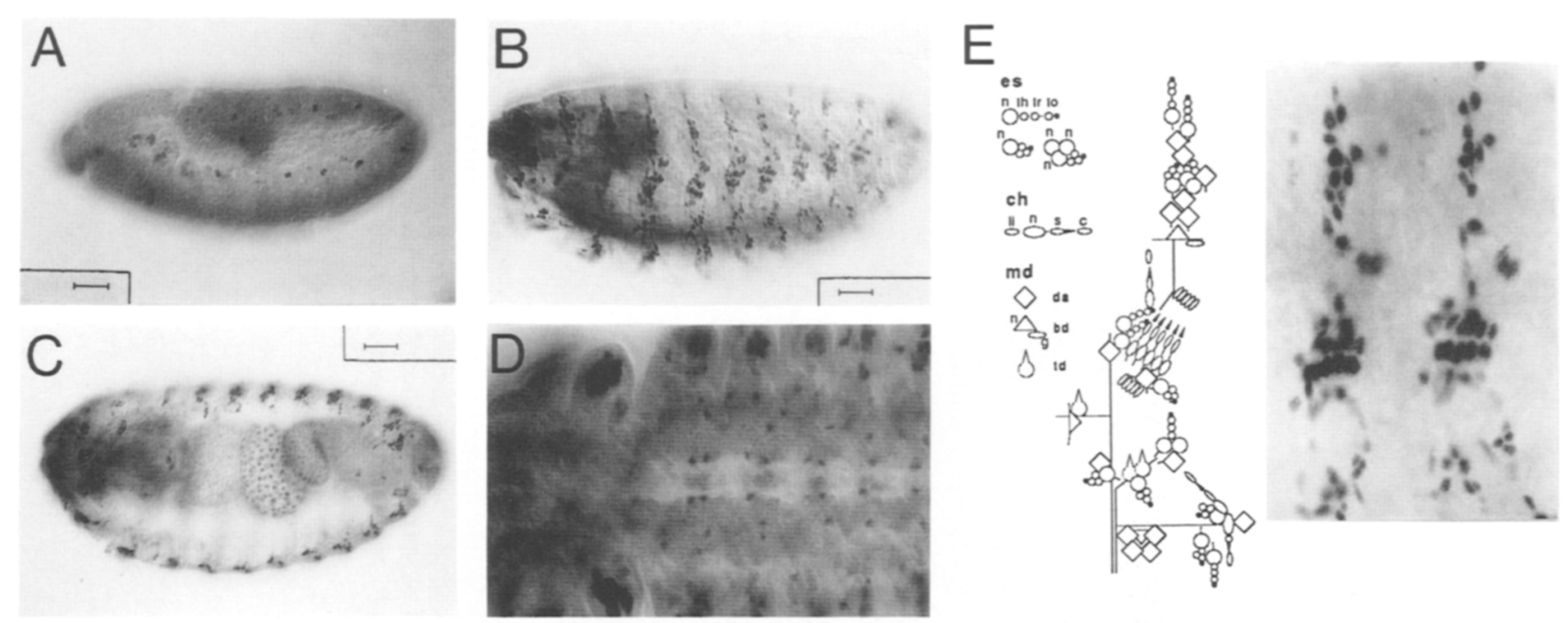

Figure 6. Expression of the Cpo protein in developing embryos. Whole-mount embryos $(A-D)$ are shown anterior to the left, dorsal up. Embryos were immunocytochemically stained with a polyclonal anti-Cpo antibody. $(A)$ An early stage- 11 embryo. Note the expression of Cpo in a pair of cells or a single cell in the posterior section of each segment. In some segments a faint labeling cell or pair of cells appears in the anterior portion. These cells correspond to neural precursors of the PNS. The Cpo protein is not observed before segmentation, whereas the $c p o$ message is. $(B)$ A stage-16 embryo. The focal plane is just below the cuticle. Note the regular expression pattern in each segment and the punctate nuclear localization. Almost all PNS cells express Cpo. $(C) \mathrm{A}$ stage-16 or -17 embryo. The focal plane is on the gut. Note the nuclear localization in the cells of the midgut. $(D)$ Detail of the anterior section of the ventral nerve cord of an embryo. Note the nuclear staining in a small subset of cells of the CNS. (E) Detail of the Cpo distribution in two abdominal segments and the corresponding diagram of the PNS (redrawn from Bodmer and Jan 1987). (es) External sensory organ; (ch) chordotonal organ; $(\mathrm{md})$ multiple dendrite neuron; $(\mathrm{n})$ neuron; $(\mathrm{th})$ thecogen cell; (tr) trichogen cell; (to) tormogen cell; (li) ligament cell; (s) scolopale cell; (c) cap cell; (da) dendritic arbor neuron; (bd) bipolar dendrite neuron; (td) trachea innervating cell. From dorsal to ventral: The dorsal cluster, the lateral cluster, and the most dorsal of the two ventral clusters are shown in a single focal plane.

To establish whether cpo expression depends on the expression of the $d a$ and AS-C genes, we localized Cpo in mutant embryos that lack almost all genes of the AS-C or the $d a$ gene. Homozygous $d a / d a$ embryos do not express Cpo in the PNS at any stage of development. However, expression of Cpo in the cells of the CNS and a small cluster of cells around the posterior spiracle is not affected (Fig. 7C). In addition, some cells of the gut also express Cpo in $d a / d a$ embryos, although this pattern is different from the wild-type pattern. From these observations we conclude that $d a$ is required for proper expression of $c p o$ in the PNS. In AS-C mutant embryos most of the cells of the PNS except the chordotonal neurons and their support cells, as well as few other neurons, fail to express Cpo (Fig. 7D). The remainder of the cpo expression pattern, glial cells of the CNS and gut, is not obviously affected. These observations show that genes of the AS-C are required for proper expression of cpo in many cells of the PNS but not in non-PNS cells. Because cpo is not expressed in many SMCs of AS-C mutant embryos (data not shown), and because genes of the AS-C are expressed in SMCs (Cabrera et al. 1987; Brand and Campos-Ortega 1988), the genes of the AS-C also control expression of cpo during early neurogenesis (see Discussion). However, after stage 13, expression of T3, T4, T5, and T8 transcripts of the AS-C cannot be detected in the cells of the PNS (Cabrera et al. 1987; Brand and CamposOrtega 1988; data not shown). It is therefore possible that once cpo expression is initiated, the Cpo protein initiates a number of events leading to transcriptional autoregulation. Two lines of evidence argue against this hypothesis. First, no difference was observed in the $\beta$-galactosidase expression pattern among $11 / 11$ or $11 /+$ embryos from the 11 enhancer detector strain at all stages tested, indicating that Cpo is not required for cpo transcription. Second, $\beta$-galactosidase staining of homozygous amorphic mutant embryos carrying a $\mathrm{P}$ element that contains most of the regulatory sequences of the cpo gene upstream of the $l a c Z$ gene (see Fig. 5) expresses the marker gene in the same cells as nonmutant embryos at all developmental stages.

\section{Discussion}

To further dissect the molecular aspects of nervous system differentiation we have screened for genes that are expressed in most or all neural precursors and the more differentiated cells of the PNS during embryogenesis. The goal of these studies is to identify genes that are controlled by the proneural genes and to unravel the molecular cascade of events that lead to a fully developed and functional PNS. Using a reverse genetic approach based on enhancer detection (for review, see Bellen et al. 1990), we have identified several genes that are expressed in all precursors of the PNS. A genetic analysis of one of these genes, cpo, indicates that the gene is essential for 

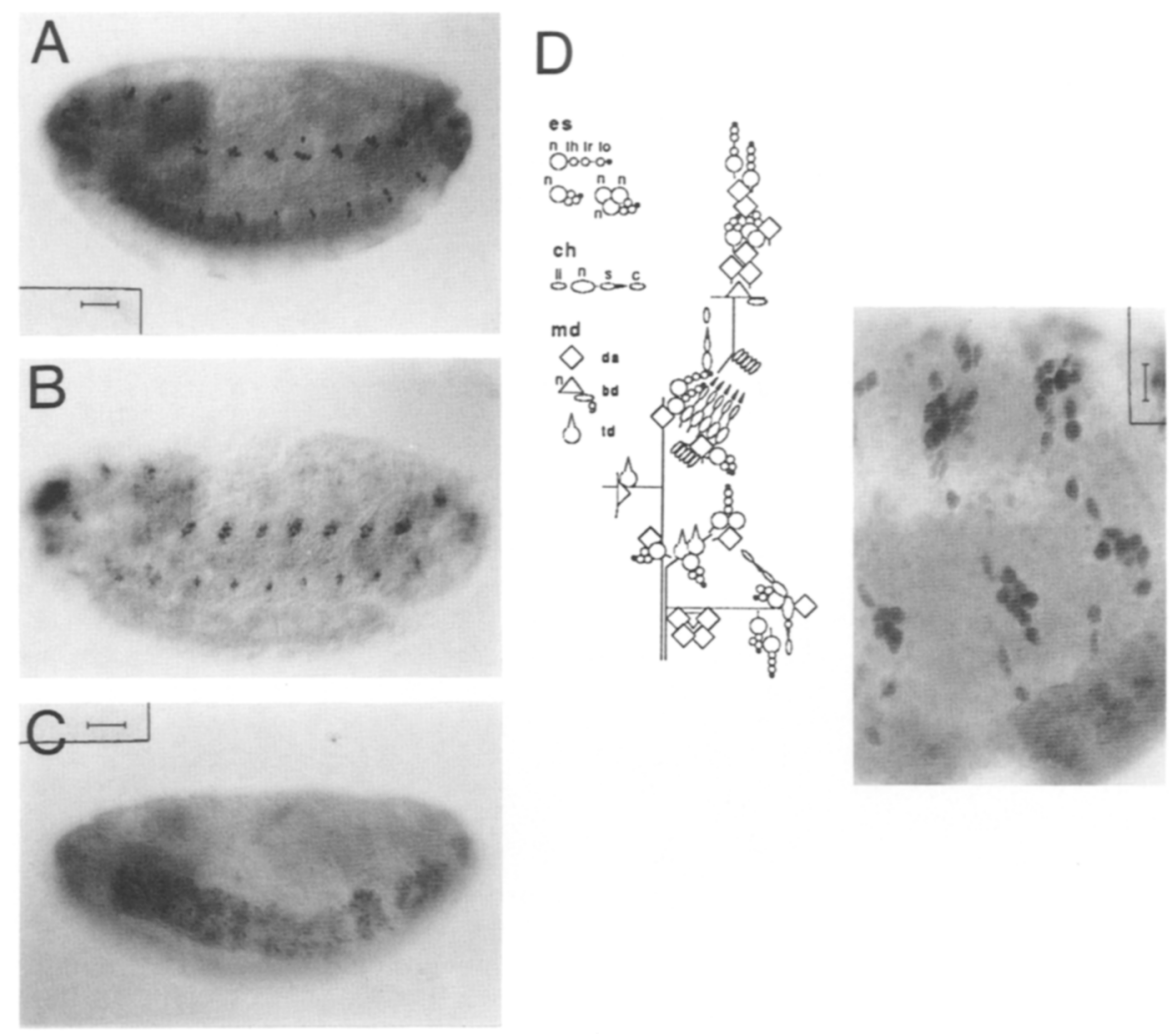

nerve cord correspond to the nuclei of the peripheral glia. The nuclei that label in the ventral and lateral cluster belong primarily to cells of the chordotonal organs. With few exceptions, other neurons or support cells cannot be identified.

embryonic development and required for normal adult behavior. However, no obvious morphological defects have been observed in the PNS. Here, we present molecular data that suggest a possible role for cpo in PNS differentiation.

Structural analysis of cpo shows a complex organization. The most conspicuous features are the presence of a very large intron with nontypical splice acceptor or donor sites (Mount et al. 1992), extensive alternative splicing, and a large exon flanked by small exons. Our analysis also indicates that cpo has two promoters upstream of exon $A 0$ and $B 1$. The large $42-\mathrm{kb}$ exon is alternatively spliced, and an unusual splice donor or splice acceptor at the boundary of exon 3-intron 3 or intron 3-exon 4 may be responsible for the splicing pattern. All enhancer detector insertions map to a 200 -bp fragment, and six enhancer detectors have inserted at exactly the same position. These six P-element insertions cause very different phenotypes depending on the type or size of the $P$ elements or their orientation. Sequence data indicate that eight insertions are located between enhancer-like sequences and the promoter of one of the transcripts, suggesting that they may interfere with the transcriptional machinery. This interference may rely on complex spatial and structural requirements for the interaction between the upstream regulatory sequences of $c p o$ and its transcription initiation site.

Sequence analysis reveals that none of the cpo cDNAs

Figure 7. Expression of Cpo in mutant embryos. Whole-mount embryos $(A-C)$ are shown anterior to the left, dorsal up. Embryos were immunocytochemically stained with a polyclonal anti-Cpo antibody $(A, C, D) .(B)$ A wild-type wholemount embryo from an in situ hybridization with a probe specific for the $17 \mathrm{cDNA}$ trailer. (A) A homozygous $11 / 11$ cpo mutant embryo at stage 15 . Note the lack of staining in all cells of the PNS except the chordotonal neurons. $(B)$ Expression pattern of the transcript that corresponds to the 17 cDNA in a stage- 16 embryos. $(C) \mathrm{A}$ homozygous $d a^{2} / d a^{2}$ embryo. These embryos show many morphological abnormalities (Caudy et al. 1988a), but Cpo expression can be detected in the nuclei of specific cells of the CNS, as well as in some midgut cells and small cluster of cells at the posterior end of the embryo. $(D)$ Detail of the posterior and ventral portion of an $s c^{B 57} / s c^{B 57}$ embryo stained with the Cpo antibody. Shown are the lateral and ventral clusters. Only one cell labels in the dorsal cluster of these embryos. (Left) A schematic drawing of the PNS. The most ventral band in the photograph is the ventral nerve cord. The cells that are most closely associated with the ventral entral and lateral cluster belong primarily to

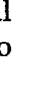

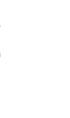


Saito and D. Anderson, pers. comm.). The high degree of amino acid sequence conservation of these domains between such evolutionarily divergent phyla as arthropods and chordates suggests a functional role for these domains beyond mere RNA binding.

The Cpo protein is localized to the nucleus in all PNS cells. Nuclear localization is in agreement with the presence of a proposed nuclear localization sequence (NLS) in the protein (90-114 amino acids). This NLS also contains the SPKR sequence. This sequence is similar to the consensus sequence that is phosphorylated by the $c d c 2$ kinase, and phosphorylation of such sites may increase the rate of nuclear accumulation of the protein (for discussion, see Robbins et al. 1991). However, a NLS may not be required because the pre-mRNA may act as nuclear retention sequences. Whichever mechanism is responsible for the nuclear localization, the presence of the protein in the nucleus agrees with the proposed function.

Analysis of Cpo protein expression in embryos that lack the proneural AS-C or da genes shows that both genes are required for proper expression in the SMCs of the PNS at germ-band extension. We have not demonstrated direct transcriptional regulation by the proneural genes. These genes are expressed in the SMCs at the same time that cpo expression is initiated (stages 9 and $10)$. Moreover, contrary to the CNS in which cell death is visible after stage 11 , no cell death has been reported in the PNS of proneural mutants (see Brand and CamposOrtega 1988). Thus, the proneural genes may directly control expression of $c p o$, either by forming a transcriptional block that is derepressed when their concentration decreases or by acting as positive transcriptional regulators when their expression becomes concentrated in the SMCs (Cubas et al. 1991; Skeath and Carroll 1991). It is unlikely that this type of regulation is taking place at later developmental stages because the proneural genes are not expressed in the PNS at these stages (Cabrera et al. 1987; Brand and Campos-Ortega 1988). Our data suggest that Cpo does not initiate an autoregulatory cascade that could maintain Cpo expression.

There are some striking similarities between cpo and the Sex-lethal (Sxl) gene. Both encode proteins with RNP-CS-type domains, and both produce through alternative splicing messages that do not contain this domain and are likely to be nonfunctional (Bell et al. 1991). Genetic evidence also indicates that both are controlled by proneural genes of the AS-C (Torres and Sanchez 1989) and the da gene (Cline 1983). Finally, both genes seem to have two (or more) promoters (Keyes et al. 1992). Sxl regulates its own splicing as well as that of the transformer gene, thereby initiating a cascade of events in sex determination and dosage compensation (for review, see Baker 1989). Because mutations in cpo do not cause obvious morphological defects in the PNS or the CNS and because $c p o$ is required for viability, we propose that $c p o$ regulates RNA processing of one or more genes that are required in the PNS and/or other cells where it is expressed. The majority of the genes that are expressed in the Drosophila nervous system are alternatively spliced, and even single-base editing of RNA has been shown to have dramatic effects on the properties of some channels (Sommer et al. 1991). Hence, alternative processing of RNAs may have an important role in nervous system function, and proteins like $\mathrm{HuD}$ (Szabo et al. 1991), ELAV (Robinow and White 1988), and Cpo may fullfill these roles.

\section{Materials and methods}

Molecular techniques

Plasmid rescue from fly DNA was performed as described by Wilson et al. (1989). Other cloning techniques, Northern and Southern analysis, and chromosomal walking were performed by standard procedures as described in Sambrook et al. (1989). For sequencing, fragments were subcloned in Bluescript KS and SK. Single- or double-stranded DNA was sequenced by the dideoxy chain-termination method (Sanger et al. 1977), with the automated fluorescence procedure (Applied Biosystems) as described by Smith et al. (1986). DNA sequence analysis was carried out by the Nucleic Acids Core in the Insititute for Molecular Genetics at Baylor College of Medicine.

\section{Fly strains and culture}

All cpo fly strains used in this study are described in Bellen et al. (1992). The AS-C deficiency strain, $D f(1) s c^{B 57} w s n^{3} / F M 6, y^{31 d}$ $d m B$, was obtained from E. Grell and Y.-N. Jan (University of California at San Francisco). The $y ; d d a^{2} / C y O$ and $D f(2 L) / 27 /$ $S M 1$ strains were obtained from A. Ghysen (University of Brussels, Belgium). Flies were cultured on standard fly food supplemented with dry yeast.

\section{Rabbit polyclonal anti-Cpo antibody}

A 949-bp XhoIl fragment from the 61.2 cDNA, which corresponds to amino acids 164-479 shown in Figure 2A, was cloned into the BamHI site of the polylinker of the pATH 1 vector (Dieckman and Tzagoloff 1985). The construct was transformed in RR1 Escherichia coli, and the fusion protein was induced as described. The fusion protein was isolated by preparative PAGE, electroleluted, dialyzed, dried, and resuspended in Freund's adjuvant. Purified protein $(100-200 \mu \mathrm{g})$ was injected twice into two New Zealand white rabbits. The preimmune and immune sera were tested on embryos and Western blots.

\section{In situ hybridization to embryos}

Digoxygenin-labeled probes were prepared as described [Boehringer Mannheim (DNA labeling and detection kit: nonradioactive)]. In situ hybridizations to whole-mount embryos were performed essentially as described previously (Tautz and Pfeifle 1989 .

\section{$X$-gal staining and $H R P /$ alkaline-phosphatase} immunocytochemistry

$\mathrm{X}$-gal staining, and anti- $\beta$-galactosidase staining with an affinity-purified polyclonal antibody (Cappel) were performed as described by Bier et al. (1989). Immunocytochemistry with other antibodies was performed in a similar manner. The secondary antibodies used in this study are an anti-mouse or an anti-rabbit antibody conjugated to horseradish peroxidase (HRP) or alkaline phosphatase (AP). Most antibodies were first preabsorbed to 0 -to 3 -hr-old embryos at a concentration $10 \times$ higher than the final concentration for $2-3 \mathrm{hr}$ at room temperature before use. The 
following rabbit polyclonal antibodies (RPAbs) were used: RPAb anti-Cpo at $1: 7,000-10,000$; RPAb anti-sense or anti-T8 at 1:5000 (Vaessin et al. 1991; M. Brand, pers. comm.). Doublelabeling experiments were performed by first completing the entire procedure with a primary and the anti-HRP secondary antibody, followed by signal detection with $\mathrm{HCl}$-diaminobenzidine in $0.12 \mathrm{M}$ Tris ( $\mathrm{pH} 7.6$ ), which leads to formation of a brown precipitate. The entire procedure was subsequently repeated with another primary antibody, again followed with an anti-HRP secondary antibody. The signal was detected with $\mathrm{HCl}$-diaminobenzidine in Tris ( $\mathrm{pH} 7.6) 0.12 \mathrm{M}$ containing $4 \%$ of $8 \mathrm{~m}$ lithium chloride, leading to the formation of a black precipitate.

\section{Immunoblotting}

Immunoblotting was essentially performed as described by Towbin et al. (1979). Embryonic extracts were separated by 10\% PAGE and transferred onto nitrocellulose. Primary antibody was used at a final concentration of $1: 5000$. Signal detection was performed with goat anti-rabbit conjugated to AP at $1: 1000$.

\section{Acknowledgments}

We thank Dan Strumpf and Linus Tsai for helping us out in the last phases of this project. We thank Harald Vaessin, Ethan Bier, Susan Sheperd, Ed Grell, and Yuh Nung Jan for help, suggestions, antibodies, and fly strains. We thank Alain Ghysen for fly strains; Ron Davis and Kai Zinn for genomic and cDNA libraries; Ron Richman for suggestions and advice; and Beth Eldon, Sue Berget, Jim Lupski, David Anderson, Juan Botas, Arthur Kania, Troy Littleton, and Karen Schulze for comments on the manuscript. This research was supported by a grant from the Muscular Dystrophy Association to H.J.B. H.J.B. is an assistant investigator of the Howard Hughes Medical Institute.

The publication costs of this article were defrayed in part by payment of page charges. This article must therefore be hereby marked "advertisement" in accordance with 18 USC section 1734 solely to indicate this fact.

\section{Note added in proof}

Sequence data in this paper have been submitted to the EMBL/ GenBank data libraries under accession numbers Z14311 for cpo 17, Z14312 for cpo 61.2, and Z14974 for cpo 61.1.

\section{References}

Baker, B.S. 1989. Sex in flies: The splice of life. Nature 340: 521-524.

Bandziulis, R.J., M.S. Swanson, and G. Dreyfuss. 1989. RNAbinding proteins as developmentally regulators. Genes \& Dev. 3: 431-437.

Bell, L.R., J.I. Horabin, P. Schedl, and T.W. Cline. 1991. Positive autoregulation of Sex-Lethal by alternative splicing maintains the female determined state in Drosophila. Cell 65: 229-239.

Bellen, H.J., C.J. O'Kane, C. Wilson, U. Grossniklaus, R.K. Pearson, and W. Gehring. 1989. P-element mediated enhancer detection: A versatile method to study development in Drosophila. Genes \& Dev. 3: 1288-1300.

Bellen, H.J., C. Wilson, and W. Gehring. 1990. Dissecting the complexity of the nervous system by enhancer detection. BioEssays 12: 199-204.
Bellen, H.J., H. Vaessin, E. Bier, A. Kolodkin, D. D'Evelyn, S. Kooyer, and Y.N. Jan. 1992. The Drosophila couch potato gene: An essential gene required for normal adult behavior. Genetics 131: 365-375.

Benson, M. and V. Pirrotta. 1988. The Drosophila zeste protein binds cooperatively to sites in many gene regulatory regions: Implications for transvection and gene regulation. $E M B O J$. 7: 3907-3915.

Bier, E., H. Vaessin, S. Shepherd, K. Lee, K. McCall, S. Barbel, L. Ackerman, R. Carretto, T. Uemura, E. Grell, L.Y. Jan, and Y.N. Jan. 1989. Searching for pattern and mutation in the Drosophila genome with a P-lacZ vector. Genes \& Dev. 3: $1273-1287$.

Biggin, M.D. and R. Tiian. 1988. Transcription factors that activate the U1trabithorax promoter in developmentally staged extracts. Cell 53: 699-711.

Biggin, M.D., S. Bickel, M. Benson, V. Pirrotta, and R. Tjian. 1988. Zeste encodes a sequence-specific transcription factor that activates the Ultrabithorax promoter in vitro. Cell 53: 713-722.

Bodmer, R. and Y.N. Jan. 1987. Morphological differentiation of the embryonic peripheral neurons in Drosophila. Wilhelm Roux's Arch. Dev. Biol. 196: 69-77.

Bodmer, R., R. Carretto, and Y. N. Jan. 1989. Neurogenesis of the peripheral nervous system in Drosophila embryos: DNA replication patterns and cell lineages. Neuron 3: 21-32.

Brand, M. and J. A. Campos-Ortega. 1988. Two groups of interrelated genes regulate early neurogenesis in Drosophila melanogaster. Wilhelm Roux's Arch. Dev. Biol. 197: 69-77.

Burtis, K.C., C.S. Thummel, C. Weldon Jones, F.D. Karim, and D.S. Hogness. 1990. The Drosophila 74E early puff contains E74, a complex ecdysone inducible gene that encodes two ets-related proteins. Cell 61: 85-99.

Cabrera, C.V., A.A. Martinez, and M. Bate. 1987. The expression of three members of the achaete-scute gene complex correlates with neuroblast segregation in Drosophila. Cell 50: $425-433$.

Campos-Ortega, J.A. and V. Hartenstein. 1985. The embryonic development of Drosophila melanogaster, Springer-Verlag, Berlin, Germany.

Caudy, M., E.H. Grell, C.C. Dambly, A. Ghysen, L.Y. Jan, and Y.N. Jan. 1988a. The maternal sex determination gene daughterless has zygotic activity necessary for the formation of peripheral neurons in Drosophila. Genes \& Dev. 2: 843852.

Caudy, M., H. Vaessin, M. Brand, R. Tuma, L.Y. Jan, and Y.N. Jan. 1988b. daughterless, a Drosophila gene essential for both neurogenesis and sex determination, has sequence similarities to myc and the achaete-scute complex. Cell 55: 1061-1067.

Cavener, D.R. 1987. Comparison of the consensus sequence flanking translational start sites in Drosophila and vertebrates. Nucleic Acids Res. 15: 1353-1361.

Cline, T.W. 1983. The interaction between daughterless and Sex-lethal in triploids: A lethal sex-transforming maternal effect linking sex determination and dosage compensation in Drosophila melanogaster. Dev. Biol. 95: 260-274.

Cubas, P., J.F. Decelis, S. Campuzano, and J. Modolell. 1991. Proneural clusters of Achaete-Scute expression and the generation of sensory organs in the Drosophila imaginal wing disc. Genes \& Dev. 5: 996-1008.

Dieckman, C.L. and A. Tzagoloff. 1985. Assembly of the mitochondrial system. J. Biol. Chem. 260: 1513-1520.

Friedman, A.D., W.H. Landschulz, and S.L. McKnight. 1989. CCAAT/enhancer binding protein activates the promoter of the serum albumin gene in cultured hepotoma cells. Genes 
\& Dev. 3: 1314-1322.

Ghysen, A. and C. Dambly-Chaudiere. 1989a. Genesis of the Drosophila peripheral nervous system. Trends Genet. 5: 251-255.

- 1989 b. Early events in the development of Drosophila peripheral nervous system. I. Physiol. (Paris) 83: 1-11.

Hann, S.R., M.W. King, D.L. Bentley, C.W. Anderson, and R.N. Eisenman. 1988. A non-AUG translational initiation in c-myc exon 1 generates an $\mathrm{N}$-terminally distinct protein whose synthesis is disrupted in Burkitt's lymphomas. Cell 52: 185-195.

Hiromi, Y. and W.J. Gehring. 1987. Regulation and function of the Drosophila segmentation gene fushi tarazu. Cell 50: 963-974.

Hultmark, D., R. Klemenz, and W.J. Gehring. 1986. Translational and transcriptional control elements in the untranslated leader of the heatshock gene hsp22. Cell 44: 429-438.

Johnson, P.F., W.H. Landschulz, B.J. Graves, and S.L. McKnight. 1987. Identification of a rat nuclear protein that binds to the enhancer core element of three animal viruses. Genes \& Dev. 1: 133-146.

Johnson, J.E., S.J. Birren, and D.J. Anderson. 1990. Two rat homologues of Drosophila achaete-scute are expressed specifically in neuronal precursors. Nature 346: 858-861.

Johnson, J.E., K. Zimmerman, T. Saito, and D.J. Anderson. 1992. Induction and repression of mammalian Achaete-Scute homologue (MASH) gene expression during neuronal differentiation of P19-embryonal carcinoma cells. Development 114: 75-86

Keyes, L.N., T.W. Cline, and P. Schedl. 1992. The primary sex determination signal of Drosophila acts at the level of transcription. Cell 68: 933-943.

Lo, L.C., J.E. Johnson, C.W. Wuenschell, T. Saito, and D.J. Anderson. 1991. Mammalian achaete-scute homolog 1 is transiently expressed by spatially restricted subsets of early neuroepithelial and neural crest cells. Genes \& Dev. 5: 1524-1537.

Mount, S.M., C. Burks, G. Hertz, G.D. Stormo, O. White, and C. Fields. 1992. Splicing signals in Drosophila: Intron size, information content, and consensus sequences. Nucleic Acids Res. (in press).

Murre, C., P. Schonleber Mc Caw, H. Vaessin, M. Caudy, L.Y. Jan, Y.N. Jan, C. Cabrera, J.N. Buskin, S.D. Hauschka, A.B. Lassar, H. Weintraub, and D. Baltimore. 1989. Interactions between heterologous helix-loop-helix proteins generate complexes that bind specifically to a common DNA sequence. Cell 58: 537-544.

O'Hare, K. and G.M. Rubin. 1983. Structures of P transposable elements and their sites of insertion and excision in the Drosophila melanogaster genome. Cell 34: 25-36.

Peabody, D.S. 1987. Translational initiation at an ACG triplet in mammalian cells. J. Biol. Chem. 262: 11847-11851.

Pirrotta, V., E. Manet, E. Hardon, S.E. Bickel, and M. Benson. 1987. Structure and sequence of the Drosophila zeste gene. EMBO 1. 6: 791-799.

Robbins, J., S.M. Dilworth, R.A. Laskey, and C. Dingwall. 1991. Two interdependent basic domains in nucleoplasmin nuclear targeting sequence: Identification of a class of bipartite nuclear targeting sequence. Cell 64: 615-623.

Robinow, S. and K. White. 1988. The locus elav of Drosophila melanogaster is expressed in neurons at all developmental stages. Dev. Biol. 126: 294-303.

Romani, S., S. Campuzano, E. Macagno, and J. Modolell. 1989. Expression of achaete and scute genes in Drosophila imaginal discs and their function in sensory organ development. Genes \& Dev. 3: 997-1007.
Sambrook, J., E.F. Fritsch, and T. Maniatis. 1989. Molecular cloning: A laboratory manual, 2nd ed. Cold Spring Harbor Laboratory Press, Cold Spring Harbor, New York.

Sanger, F., S. Nicklen, and A.R. Coulson. 1977. DNA sequencing with chain-terminating inhibitors. Proc. Natl. Acad. Sci. 74: 5463-5468.

Shugihara, H., V. Andrisani, and P.M. Salvaterra. 1990. Drosophila, choline acetyltransferase uses a non-AUG initiation codon and full length RNA is inefficiently translated. J. Biol. Chem. 265: 21714-21719.

Skeath, J.B. and S.B. Carroll. 1991. Regulation of Achaete-Scute gene expression and sensory organ pattern formation in the Drosophila wing. Genes \& Dev. 5: 984-995.

Smith, L.M., J.Z. Sanders, R.J. Kaiser, P. Hughes, C. Dodd, C.R. Connell, C. Heiner, S.B.H. Kent, and L.E. Hood. 1986. Fluorescence detection in automated DNA sequence analysis. Nature 321: 674-679.

Sommer, B., M. Kohler, R. Sprengel, and P.H. Seeburg. 1991. RNA editing in brain controls a determinant of ion flow in glutamate-gated channels. Cell 67: 11-20.

Swanson, M.S., T.Y. Nakagawa, K. LeVan, and G. Dreyfuss. 1987. Primary structure of human nuclear ribonucleoprotein particles $\mathrm{C}$ proteins: Conservation of sequence and domain structures in heterozygous nuclear RNA, mRNA and prerRNA-binding proteins. Mol. Cell. Biol. 7: 1731-1739.

Szabo, A., J. Dalmau, G. Manley, M. Rosenfeld, E. Wong, J. Henson, J. Posner, and H.M. Furneaux. 1991. HuD, a paraneoplastic encephalomyelitis antigen, contains RNA-binding domains and is homologous to ELAV and Sex-lethal. Cell 67: 325-333.

Tautz, D. and C. Pfeifle. 1989. A non-radioactive in situ hybridization method for the localization of specific RNAs in Drosophila embryos reveals translational control of the segmentation gene hunchback. Chromosoma 98: 81-85.

Torres, M. and L. Sanchez. 1989. The scute (T4) gene acts as a numerator element of the $\mathrm{X}:$ A signal that determines the state of activity of Sex-lethal in Drosophila. EMBO J. 8: 3079-3086.

Towbin, H., T. Staehelin, and J. Gordon. 1979. Electrophoretic transfer of proteins from polyacrylamide gels to nitrocellulose sheets: Procedures and some applications. Proc. Natl. Acad. Sci. 76: 4350-4354.

Vaessin, H., E. Grell, E. Wolff, E. Bier, L.Y. Jan, and Y.N. Jan. 1991. prospero is expressed in neuronal precursors and encodes a nuclear protein that is involved in the control of axonal outgrowth in Drosophila. Cell 67: 941-954.

Wharton, K.A., K.M. Johansen, T. Xu, and S. Artavanis-Tsakonas. 1985. Nucleotide sequence from the neurogenic locus Notch implies a gene product that shares homology with proteins containing EGF-like repeats. Cell 43: 567-581.

Wilson, C., R.K. Pearson, H.J. Bellen, C.J. O'Kane, U. Grossniklaus, and W.J. Gehring. 1989. P-element-mediated enhancer detection: An efficient method for isolating and characterizing developmentally regulated genes in Drosophila. Genes \& Dev. 3: 1301-1313.

Zinn, K., L. McAllister, and C.S. Goodman. 1988. Sequence analysis and neuronal expression of fasciclin I in grasshopper and Drosophila. Cell 53: 577-587. 


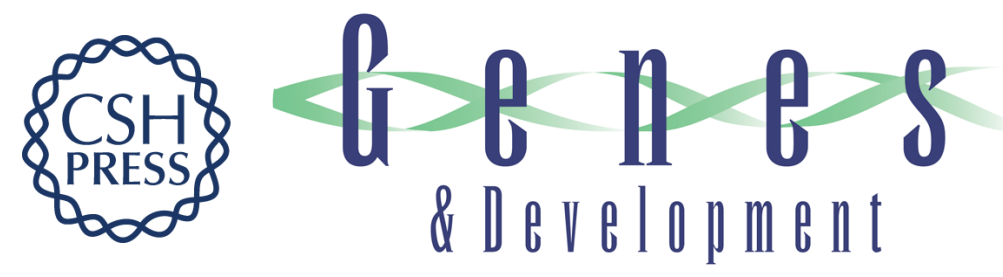

\section{The Drosophila couch potato protein is expressed in nuclei of peripheral neuronal precursors and shows homology to RNA-binding proteins.}

H J Bellen, S Kooyer, D D'Evelyn, et al.

Genes Dev. 1992, 6:

Access the most recent version at doi:10.1101/gad.6.11.2125

$\begin{array}{ll}\text { References } & \begin{array}{l}\text { This article cites } 53 \text { articles, } 19 \text { of which can be accessed free at: } \\ \text { http://genesdev.cshlp.org/content/6/11/2125.full.html\#ref-list-1 }\end{array}\end{array}$

License

Email Alerting Receive free email alerts when new articles cite this article - sign up in the box at the top Service right corner of the article or click here.

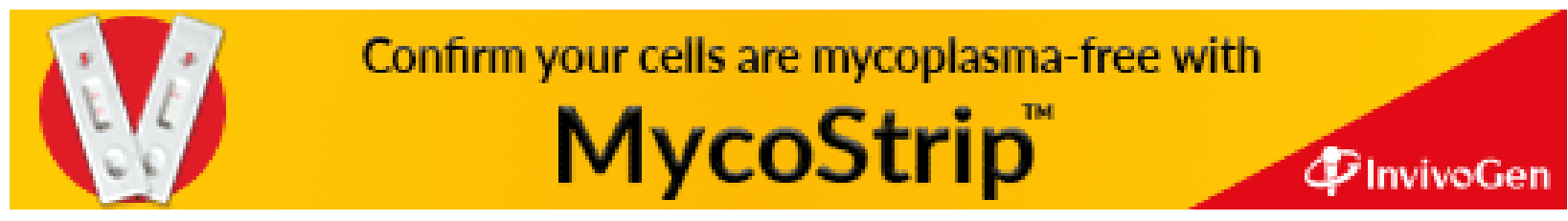

